\title{
Recent Applications Of da Vinci Robotic Biomedical Technology in the Field of Surgery: A Mini-Review
}

\author{
Omer Faruk Ozkan, Ethem Unal*, Sema Yuksekdag, Abdullah Yildiz and Neset Koksal \\ Department of General Surgery, Istanbul, Turkey
}

*Corresponding author: Ethem Unal, Department of General Surgery, Istanbul, Turkey

\begin{tabular}{|c|c|}
\hline ARTICLE INFO & ABSTRACT \\
\hline Received: 慧 April 17, 2019 & Citation: Omer Faruk Ozkan, Ethem Unal, Sema Yuksekdag, Abdullah Yildiz, Neset Koksal. \\
\hline Published: April 23, 2019 & $\begin{array}{l}\text { Recent Applications Of da Vinci Robotic Biomedical Technology in the Field of Surgery: A } \\
\text { Mini-Review. Biomed J Sci \& Tech Res 17(2)-2019. BJSTR. MS.ID.002989. }\end{array}$ \\
\hline
\end{tabular}

\section{Mini Review}

Based on the most recent developments in the robotic surgery since 2001, we conducted a search of the current literature on the da Vinci applications in all fields of surgery. The new devices invented by biomedical engineering experts provides a vast field of vision in Da Vinci robotic technology. The high-quality standard of the current Da Vinci series (SI, X, XI) including the recent types of consoles (closed/open), arrangement of robotic arms (single/ multiple), types of three-dimensional videosystem (mirror/ocular/ polarizing glasses) has improved the success of operations and patients' satisfaction [1]. In gynecology, robot-assisted laparoscopy is successfully used for advanced staged endometrial cancer, staging of early-ovarian cancer, and pelvic exenteration in case of recurrent malignancies [2]. Furthermore, more recent robots have allowed performing sentinel node biopsy in endometrial or cervical cancer, as well. In general surgery, robotic transanal minimally invasive surgery for rectal cancer and robotic hernia repair including both transabdominal preperitoneal repair (TAPP) and intraperitoneal onlay mesh (IPOM) are the most recent developments [3, 4].

Da Vinci Xi four-arm approach for minimally invasive esophagectomy in both benign and malign tumors, resections in hepatobiliary surgery (hepatectomy for primary or metastatic liver tumors, cholecystectomy), and the other applications from colorectal surgery (colectomy) to endocrine surgery (thymectomy to surrenalectomy) shows the wide range of robotic applications in this field [5-7]. Robotic nephrectomies and radical prostatectomies are among the most common procedures in the field of Urology [8]. Robotic surgery provides better or similar postoperative outcomes to open or laparoscopic surgery, respectively. The advantage of the system is best seen in narrow areas difficult to access, and when dissecting anatomical structures with adhesions. However, costs are currently very high. Increased competition among not a few manufacturers and wider acceptance of this biomedical technology may drive the costs down. In the near future, robotics can have a significant impact on microsurgery as novel technologies enable the diagnosis and treatment of diseases at earlier stages. We believe that robotic microsurgery will be one of the key components of future surgical interventions in the fields of cardiothoracic surgery, reconstructive plastic surgery, ophthalmology, neurosurgery, and otolaryngology, as well.

\section{References}

1. Rassweiler JJ, Goezen AS, Rassweiler Seyfried MC, Liatsikos E, Bach T, et al. Robots in urology-an analysis of current and future devices. Urologe A 57(9): 1075-1090.

2. Ngo C, Cornou C, Rossi L, Bats AS, Bensaid C, et al. (2016) Evidence for the use of robotically assisted surgery in gynecologic cancers. Curr Opin Oncol 28(5): 398-403.

3. Ngu JC, Kuo LJ, Kung CH, Chen CL, Kuo CC, et al. (2018) Robotic transanal minimally invasive surgery for rectal cancer after clinical complete response to neoadjuvant chemoradiation. Int J Med Robot 14(5): e1948.

4. Tian W, Fei Y (2018) Application of Da Vinci robotic surgery to hernia repair. Zhonghua Wei Chang Wai Ke Za Zhi 21(7): 740-743.

5. Tomulescu V, Stanescu C, Blajut C, Barbulescu L, Droc G, et al. (2018) Robotic Approach in Benign and Malignant Esophageal Tumors; A Preliminary Seven Case Series. Chirurgia (Bucur) 113(2): 202-209.

6. Chandarana M, Patkar S, Tamhankar A, Garg S, Bhandare M, et al. (2017) Robotic resections in hepatobiliary oncology - initial experience with Xi da Vinci system in India. Indian J Cancer 54(1): 52-55.

7. Bodner J, Augustin F, Wykypiel H, Fish J, Muehlmann G, et al. (2005) The da Vinci robotic system for general surgical applications: a critical interim appraisal. Swiss Med Wkly 135(45-46): 674-678.

8. Ng AT, Tam PC (2014) Current status of robot-assisted surgery. Hong Kong Med J 20(3): 241-250. 
ISSN: 2574-1241

DOI: 10.26717/BJSTR.2019.17.002989

Ethem Unal. Biomed J Sci \& Tech Res

(c) (P) This work is licensed under Creative

Submission Link: https://biomedres.us/submit-manuscript.php

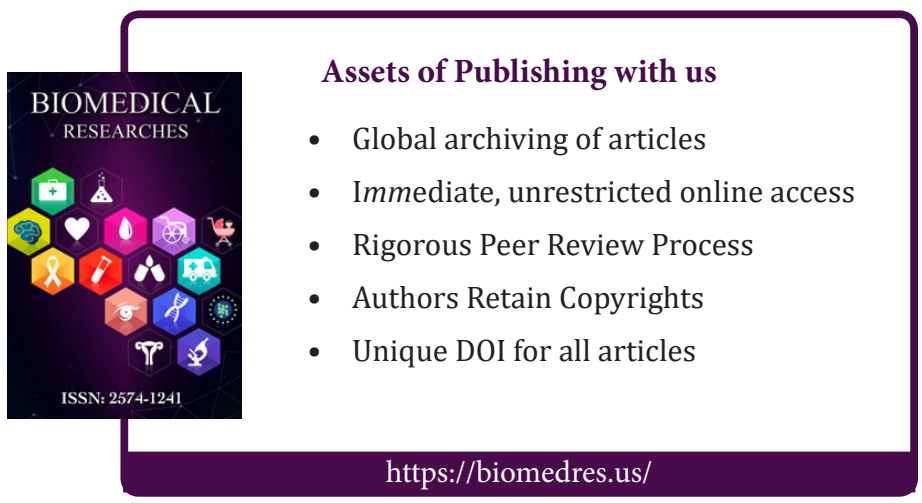

